\title{
SEIR Based Epidemic Modeling of COVID-19 in Turkey
}

\author{
Kevser Sahinbas $^{1 *}$, Ferhat Ozgur Catak ${ }^{2}$

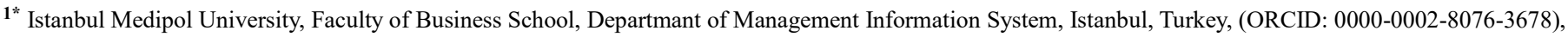 \\ ksahinbas@medipol.edu.tr \\ ${ }^{2}$ University of Stavanger, Faculty of Science and Technology, Departmant of Electrical Engineering and Computer Science, Stavanger, Norway, (ORCID: 0000-0002- \\ 2434-9966), f.ozgur.catak@uis.no
}

(First received 20 December 2020 and in final form 05 January 2022)

(DOI: 10.31590 /ejosat.842560)

ATIF/REFERENCE: Sahinbas, K., Catak, F. O. (2022). SEIR Based Epidemic Modeling of COVID-19 in Turkey. European Journal of Science and Technology, (33), 306-310.

\begin{abstract}
The coronavirus disease 2019 (COVID-19) outbreak was declared as an international pandemic rather than a local epidemic worldwide due to its rapid spread and high mortality. Countries have planned to return a new normal under some specific situations cope with economic effects that caused by the curfew and closure of companies when they reach the infection peak. Modeling the incidence of infectious diseases has attracted increasing attention from both scientific community and governments and a significant part of public health and intervention planning and have become a hot research topic in the last decades. Since epidemic diseases are effective in large populations, mathematical modeling has been used for a long time and has made important contributions in the analysis of these populations, in determining and controlling the spread rate of the epidemic. In this paper, we propose an extended model and calibrate the model and fitting with the coronavirus data by concerning with Susceptible-Exposed-Infected-Recovered (SEIR) model. In this study, we used an open public dataset to create a SEIR model for Turkey. This paper focuses on demonstrating the spreade of disease in Turkey. We gathered best approximation with the SEIR model parameters. The results suggest that SEIR model requires additional variables to model diasese spread accurately. Furthermore, the model needs to consist of data that always be the same case definition. The model plot results indicate the similar pattern.
\end{abstract}

Keywords: Epidemic model, Mathematical Model, SEIR, Covid-19 infectious disease.

\section{Türkiye'de COVID-19'un SEIR Temelli Salgın Modellemesi}

\section{$\ddot{O} z$}

Koronavirüs hastalığı 2019 (COVID-19) salgını, hızlı yayılması ve yüksek ölüm oranı nedeniyle dünya çapında yerel bir salgıı olmaktan çok uluslararası bir pandemi olarak ilan edilmiştir. Bulaşıcı hastalıkların görülme sıklığının modellenmesi hem bilim alanının hem de hükümetlerin, halk sağlığı ve müdahale planlamasının önemli bir bölümünün oldukça ilgisini çekmiş ve son on yılda önemli bir araştırma konusu haline gelmiştir. Bu çalışmada, COVID-19 için SEIR modeliyle ilgili olarak genişletilmiş bir model önermekte, modeli ve koronavirüs verileriyle uyumlu hale getirmekteyiz. Bu çalışmada, Türkiye için bir SEIR modeli oluşturmak için kamuya açık bir veri seti kullandık. Bu çalışma Türkiye'de COVID-19 hastalığının yayılışını göstermeye odaklanmaktadır. SEIR model parametreleri ile en iyi yaklaşımını göstermekteyiz. Sonuçlar, SEIR modelinin yayılmasını doğru bir şekilde modellemek için ek değişkenler gerektirdiğini göstermektedir. Ayrıca, modelin her zaman aynı vaka tanımı olan verilerden oluşması gerekliliğine inanmaktayız. Modelimizin grafiğine baktığımızda benzer desen modeli gözlemlenmiştir.

Anahtar Kelimeler: Bulaşıcı hastalık modeli, Matematiksel model, SEIR, Covid-19 bulaşıcı hastalık.

\footnotetext{
* Corresponding Author: ksahinbas@,medipol.edu.tr
} 


\section{Introduction}

In December 2019, disease of COVID-19 arised from Wuhan and spread in all around the world (Kermack \& McKendrick, 1927). This disease has caused significant public health difficulties (Bailey, 1975). Mathematical modeling the epidemic of COVID-19 can ensure efiicient strategies to cope with transmission of COVID-19. In their first studies in 1927, Kermack and McKendrick assumed that all individuals in a society were initially not immune to a certain disease and had the potential to develop the disease. In addition, they divided the society into 3 separate groups: individuals susceptible to disease (S), those who are infected and in the position of transmitting the disease (I), and individuals who have recovered from the ilness (R). These studies by Kermack and McKendrick led to the emergence of the field of Mathematical Epidemiology and new studies have emerged in this field (Kermack \& McKendrick, 1927; Bailey, 1975). However, with the emergence of various epidemic diseases today, these mathematical models have become more and more complex. While the study of Kermack and McKendrick was referred to as the SIR model in the literature due to the divisions of the society during modeling, the need to develop different models due to the mode of transmission of the disease, spread factors and other situations that should be considered. For example, it has sometimes been necessary to consider different groups in the community, such as individuals with passive immunity $(\mathrm{M})$ or individuals who are not yet infectious due to the type of disease (E), despite the disease being infected. In recent years, epidemic diseases have been studied and modeled in subcategories such as SI, SIR, SIS, SIRS, SEIS, SEIR, SEIRS, MSIR, MSEIR have been created in the literature and some studies have been applied (Kermack \& McKendrick, 1927; Bailey, 1975, Zhang, Xiang \& Meng, 2014; Arino, McCluskey, Driessche, 2003).

Important mathematical models created considering epidemic diseases are examined in sub-categories such as SIR, SIS, SIRS, SEIS, SEIR, MSIR, MSEIR and SI (Diekmann \& Heesterbeek, 2000; Keeling, 2004; Keeling, 2004; Jackson, 1989; Keshet, 2005; Hethcote, 2000; Sattenspiel \& Lloyd, 2009). In recent days, The COVID-19 outbreak encourages the models of asymptotic approaches for epidemic model. In this study, we extended the SIR model that has success in a closed-form solution to SEIR model. Consider that individuals in a population at any time t-time fall into four main groups: healthy individuals, those who are affected by the disease but are not yet infectious, those who have the capacity to transmit the disease, and those who have recovered. At any time, $\mathrm{t}$, the numbers of these individuals are $S(t), E(t), I(t)$ and $R(t)$, respectively, and the total population is $N(t)=S(t)+E(t)+I(t)+R(t)$. The classical SEIR model considers four elements that are $\mathrm{S}$ for susceptible population, $\mathrm{E}$ for interacting with an exposed population, I for infected population and $\mathrm{R}$ for recovered population $\mathrm{R}$. The equation of SEIR means the total number of people. Consequently, SEIR model provides a fundamental model for the analyze of different kinds of epidemic. Figure 1 presents the SEIR model for Covid19 transmission for the SEIR model.

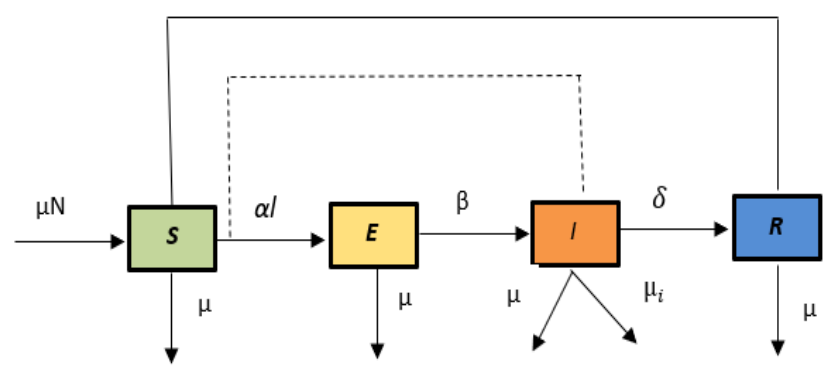

Figure 1. Mathematical Model of SEIR transmission for COVID-19 (Annas \& et al., 2020)

The mathematical model of SEIR is denoted by (Annas \& et all, 2020)

$$
\begin{gathered}
\frac{d S}{d t}=\mu N-(\alpha l+\mu+v) S \\
\frac{d E}{d t}=\alpha l S-(\beta+\mu) E \\
\frac{d l}{d t}=\beta E-\left(\mu_{i}+\delta+\mu\right) l \\
\frac{d R}{d t}=\delta 1+v S-\mu R
\end{gathered}
$$

Table 1. Definition of Variable/parameter

\begin{tabular}{|c|l|}
\hline Variable/Parameter & Definition \\
\hline$N$ & Human populations number \\
\hline$S$ & Suspected populations number \\
\hline$E$ & Exposed populations number \\
\hline$I$ & Infected Population number \\
\hline$R$ & Recovered Population number \\
\hline$\mu$ & Birth/death population rate \\
\hline$A$ & Probably of changing from S to E \\
\hline$B$ & Probably of changing from E to I \\
\hline$\mu_{i}$ & $\begin{array}{l}\text { Death population by COVID-19 } \\
\text { rate }\end{array}$ \\
\hline$\Delta$ & Probably of changing from I to R \\
\hline$V$ & Suspected Population vaccine \\
\hline
\end{tabular}

\section{Related Work}

In this study, we present a summary of the surveyed modelling infectious diseases and epidemic model example. Examples of studies with epidemic diseases are mathematical models created for the mouth and foot disease epidemic that erupted in Great Britain in 2001 and the SARS epidemic 2002 2003. Mathematical modeling of SIR, SEIR, SIRS and SEIRS models for the transmission of epidemics such as HIV-AIDS, dengue fever, diabetes and tuberculosis has been conducted in the literature (Egonmwan \& Okuonghae, 2018; Abdallah, \& et al., 2012; Tang, \& et al., 2020; Syafruddin, \& et al., 2017; Elif, Arzu, $\&$ Nuri, 2011).

In recent days, different mathematical models have attracted increasing attention to analyze the epidemic of COVID-19. It is 
noticed that some mathematical models have applied some changes based on the SEIR model (Stehle, \& et al., 2011). Mathematical modeling study was carried out on the spread of COVID-19, which is called SEIRV mathematical modeling, considering environmental factors in Wuhan, China (Yang \& Wang, 2020). Liu et al. provided a SEIRU and SEIRUd model for the COVID-19 outbreak in China, enabling the implementation of significant state public restrictions arranged to reduce the spread of the epidemic in commenting the number of detected disease transmission cases and asymptomatic infectious cases. Annas et al. implemented a SEIR model for COVID-19, taking into account the vaccination and isolation factors as the model parameters of Covid in Indonesia. They proposed a model for early precaution of the spread of COVID-19 in Indonesia as a reference, and in the following days provided a predict picture of the number of COVID-19. The findings from result indicated that vaccine may speed up recovery from COVID-19, besides they concluded that maximum restriction about isolation can decelerete the spread of COVID-19. Weinstein et al. provided an analytical model by using SEIR epidemic model, thanks to its application to the COVID-19 pandemic.

\section{Material and Method}

\subsection{Dataset}

The data is based on the study of the COVID-19 pandemic in Turkey between February and October 2020. Because of the COVID-19 virus, the government of Turkey adopted a new strategy in January 2021. The data used in this study is the number of people who got the COVID-19 virus, the number of people who have died from the COVID-19 virus and the number of people who the COVID-19 virus has infected. We applied the leastsquares method to find the best SEIR parameters with the public dataset. The results show that the model performs well and is highly reliable. However, the model is sensitive, and the model may need some fine-tuning. The SEIR approach will also need to be developed in future studies to identify more optimal parameters in order to achieve better predictions and results. The experiments are done using Python and scientific computing with NumPy, scipy and lmfit libraries.

\subsection{System Overview}

This study aims to present SEIR model of patients diagnosed with COVID-19 by collecting a publicly available dataset of patient records. Figure 2 illustrates patient records collected from several hospitals. The first stage starts with determining the best parameters to built SEIR model. At the end of the stage, model results are illustrated by graphical diagram.

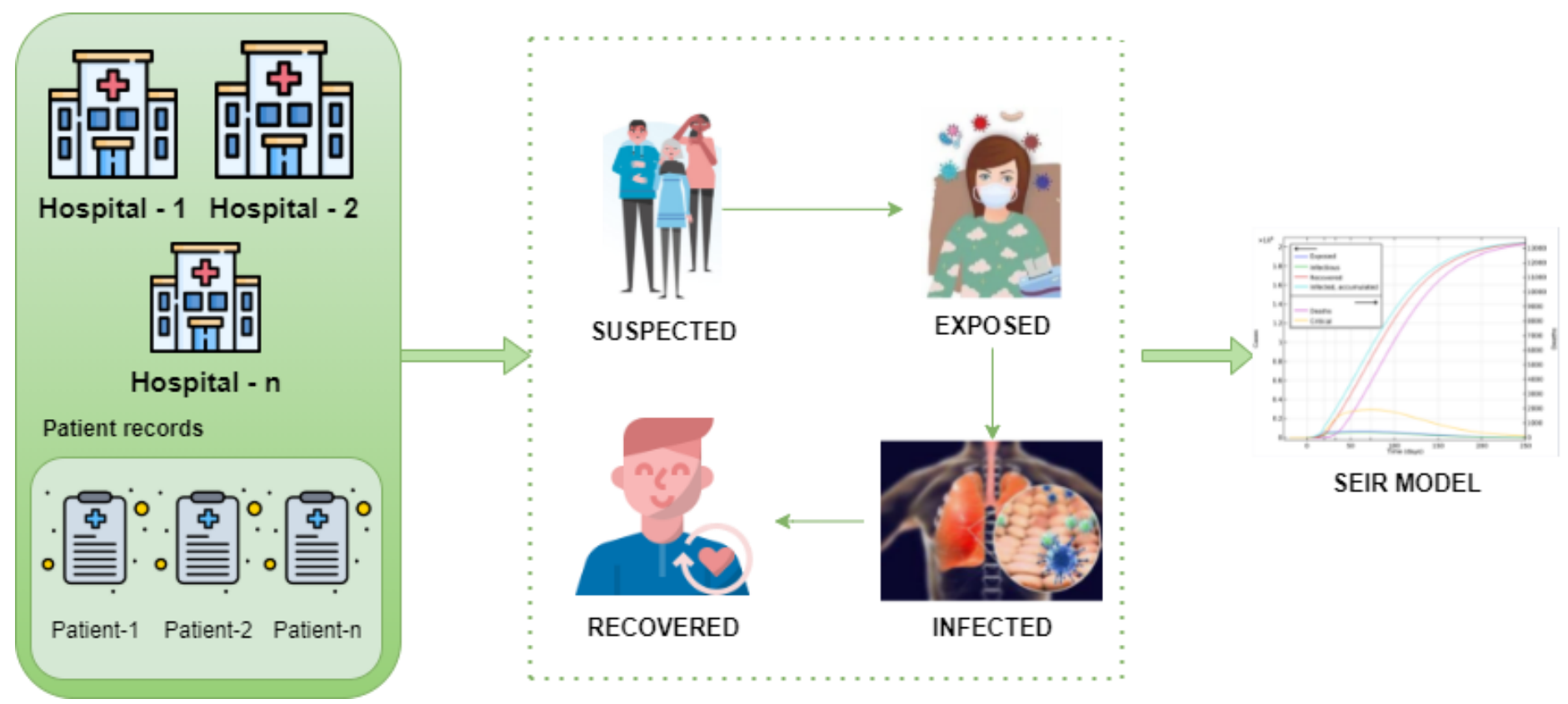

Figure 2. SEIR Model of COVID-19 


\section{Results and Discussion}

\subsection{Experiments}

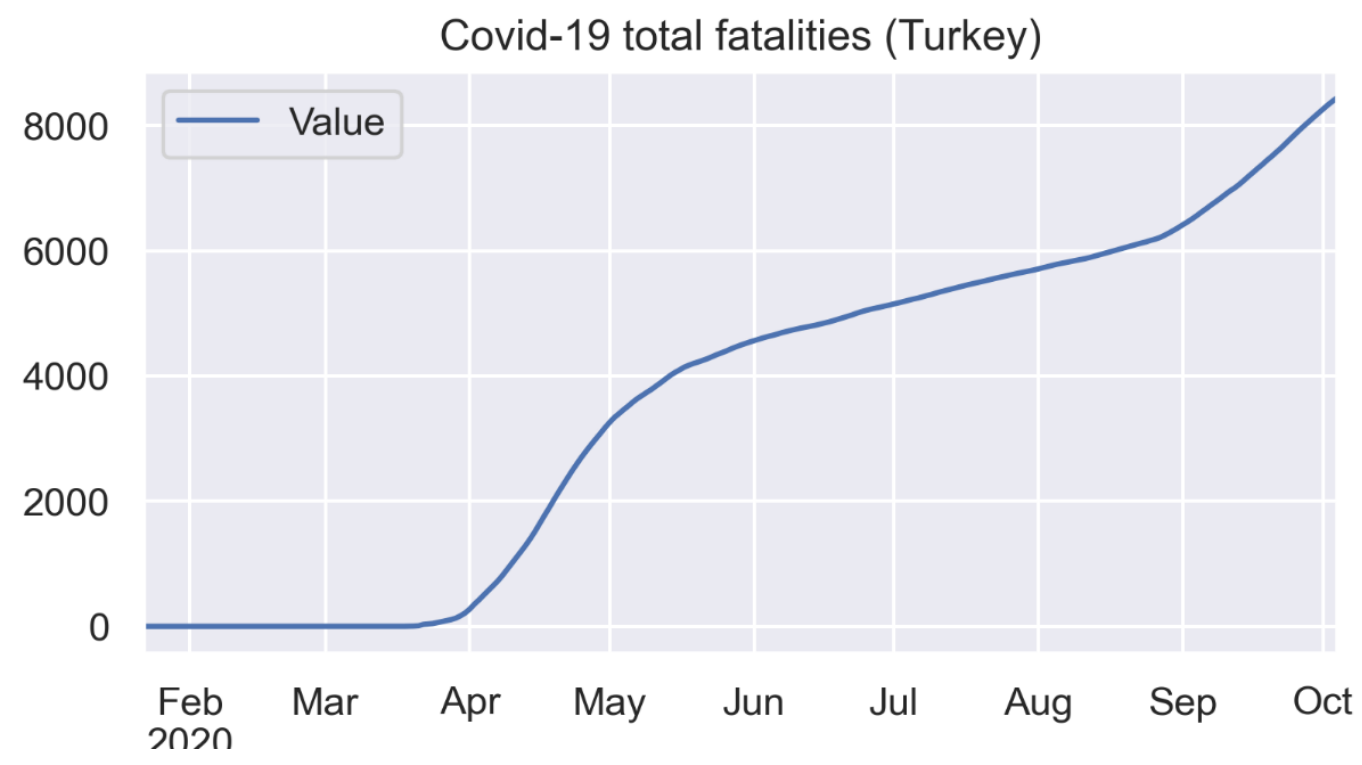

Figure 3. Covid-19 total fatalities

Figure 3 presents Covid-19 total fatalities from January to October 2020. During this period, the outbreak spread through different cities in Turkey. The figure can be divided into four parts: from February to April of 2020, from April to mid of May of 2020, from the middle of May to September of 2020 and finally from September to October of 2020. In each section of the figure, there is a linear relationship between cumulative fatalities and the respective day. This relationship seems more apparent after April to mid of May. In particular, during this period, the total fatalities increasing with time.

We obtained the best approximation with the SEIR model with following parameters. We computed the mean square error value for the observed fatalities per day and the estimated total number of fatalities at the SEIR model to obtain the best matching parameters. The grid search-based optimisation method was used to get the best parameters for the SEIR model.
This optimisation method is based on the procedure that minimises the error by applying all possible combinations. Table 2 shows the best parameters for SEIR model.

Table 2. The best parameters of SEIR model

\begin{tabular}{|l|l|}
\hline Variable & Value \\
\hline R0 & 1.03 \\
\hline Gamma & 0.753 \\
\hline Sigma & 0.391 \\
\hline
\end{tabular}

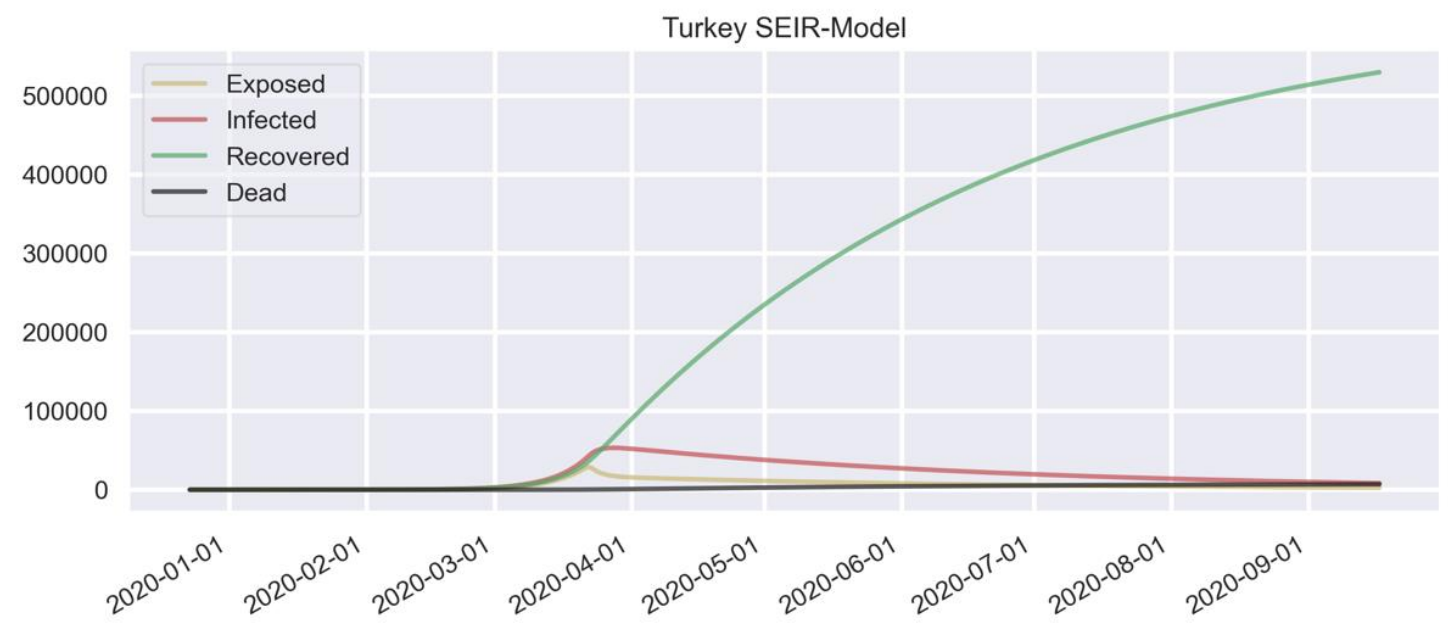

Figure 4. Turkey SEIR model for COVID-19 
It can be observed that in Figure 4, although the graphic produces similar results in disease spread, it also demonstrates some differences in the disease spread to humans. The reason for the differences in disease spread between humans and the same populations is that the number of the variable of the SEIR model is insufficient to model the spread of the disease. Thus, we suggest that additional new variables for the SEIR model are needed to model appropriately. To better understand how the disease spread to humans, it is necessary to consider some of the relevant factors that are not present in the analysis.

\section{Conclusions and Recommendations}

Covid-19 outbreak was declared as an international pandemic rather than a local epidemic worldwide due to its rapid spread and high mortality. Undoubtedly, new infectious diseases will be faced in the future. Obviously, increasing international travel and changes in social and economic patterns will result in the emergence of new and existing infectious diseases. This study presents a mathematical model for the spread of COVID-19 in Turkey. The model provides a useful tool for understanding and quantifying the spread of infectious diseases.

The emergence of new and deadly forms of infectious diseases has increased the need to develop, diversify and develop new methods used to guide disease response. Currently, various mathematical models have been applied to investigate the COVID-19 outbreak. In this study, we concern with propagation model of the COVID 19 epidemic spreade in Turkey using SEIR approach and a publicly available dataset. The findings suggest that SEIR model requires additional variables for the model. We believe that the model requires always same case definition not to give some differences due to changes definition of the cases In Turkey. The model reveals that there is similar pattern.

The model provides a good opportunity for predicting the spread of infectious diseases in the future. The model provides a useful tool for understanding and quantifying the spread of infectious diseases, which may be applied in the future when similar situations arise.

\section{References}

Annas, S., Rifandi, P., Sanusi, W., Side, S. (2020). Stability analysis and numerical simulation of SEIR model for pandemic COVID-19 spread in Indonesia, Chaos, Solitons and Fractals, 139.

Arino, J., McCluskey, C.C., wan den Driessche, P. (2003). Global results for an epidemic model with vaccination that exhibits backward bifurcation, SIAM J. Appl. Math., 64, 260-276.

Bailey, N. (1975). The mathematical theory of infectious diseases and its applications, Griffin, 28,479-480.

Diekmann., O., Heesterbeek, J.A.P. (2000). Mathematical Epidemiology of Infectious Diseases, Model Building, Analysis and Interpretation, Wiley.

Egonmwan, A. O, Okuonghae, D. (2018). Analysis of a mathematical model for tuberculosis with diagnosis, $J \mathrm{Appl}$ Math Comput, 59, 129-62.

Elif, D., Arzu, U., Nuri, O. (2011), A fractional order SEIR model with density dependent death rate. Hacet J Math Stat, 40(2), 287-95.

Hethcote, H.W. (2000). The Mathematics of Infectious Disease, SIAM Review, 42, 653.
Jackson, A. (1989). Modeling the Aids Epidemic, Notices of the American Mathematical Society, 36, 983.

Keeling, M. (2004). The mathematics of diseases, http://plus.maths.org (Date accessed: May 2020).

Kermack, W.O., \& McKendrick, A. (1927). A Contribution to the Mathematical Theory of Epidemics. Proceedings of the Royal Society of London. Series A, Containing Papers of a Mathematical and Physical Character, 115(772), 700-721.

Keshet, L. (2005). Mathematical Models in Biology, SIAM, 586.

Liu, Z., Magal, P., Seydi, O., Webb, G. (2020). A COVID-19 epidemic model with latency period, Infectious Disease Modelling, 5, 323-337.

Sattenspiel, L., Lloyd, A. (2009). The Geographic Spread of Infectious Disease, Models and Applications, NJ Princeton University Press, 304.

Stehle, J., Voirin, N., Barrat, A., Cattuto, C., Colizza, V., Isella, L., Regis, C., Pinton, J. F., Khanafer, N., Van den Broeck, W., Vanhems, P. (2011) Simulation of an SEIR infectious disease model on the dynamic contact network of conference attendees. BMC Med, 9, 87.

Syafruddin, S., Mulbar, U., Sidjara, S., Sanusi, W. (2017). A SEIR Model for transmission of tuberculosis. AIP conference proceedings, 1830.

Tang, B., Wang, X., Li, Q., Bragazzi, N.L., Tangi S , Xiao, Y, et al. Estimation of the transmission risk of $2019-\mathrm{nCoV}$ and its implication for public health interventions. J Clin Med 9, 462.

Waziri, A. S., Massawe, E. S., Makinde, O. (2012). Mathematical modelling of HIV/AIDS dynamics with treatment and vertical transmission, Appl Math, 3, 77-89.

Weinstein, S., J., Morgan, S., Rogers, K. E., Barlow, N.S. (2020). Analytic solution of the SEIR epidemic model via asymptotic approximant, Physica D, 411 .

Yang, C., Wang, J. (2020). A mathematical model for the novel coronavirus epidemic in Wuhan, China. Math Biosci Eng, 17(3), 2708-24.

Zhang, X., Xiang, H. \& Meng, X. (2014). Dynamics of the deterministic and stochastic SIQS epidemic model wiht nonlinear incidence, Appl. Math. Comput., 243, 546-558. 